Ärztliche Erfahrung beschränkt sich nicht auf medizinisches Fachwissen.

Sie entsteht auch aus den mehr oder minder alltäglichen, heiter,

\title{
Vom Doktor kam das schönste Geschenk
}

—Weihnachtlich wird mir zumute, wenn ich an einen Patienten von mir zurückdenke. Für immer ans Bett gefesselt,

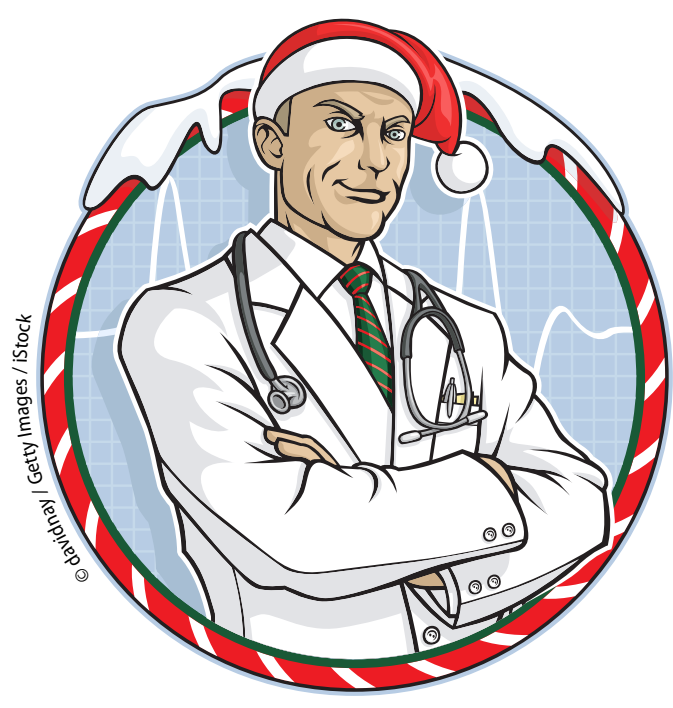

war das Lesen sein Leben geworden. Er ging ganz in seinen Büchern auf. Doch wurde ihm auch diese Freude schließlich getrübt, als sich eine Katarakt in seinem linken Auge entwickelte.

Ich schlug ihm eine Operation vor, doch der Patient wehrte sofort ab: „Nein danke, bei meiner Mutter ist das damals schiefgegangen!“ Ich versuchte es mit argumentativer Logik: „Wie viel schlimmer kann es denn werden, als überhaupt nichts zu sehen?" Das hat ihn überzeugt, und er erlaubte mir, den Eingriff ins Rollen zu bringen.

Wir mussten nicht, wie einst der Medicus bei Noah Gordon, zum Hakim nach Isfahan reisen. Nein, im schönen Krankenhaus in meiner Nachbarschaft saß ja mein lieber Kollege, der schon so manches Auge wieder in Ordnung ge- bracht hatte. Den würde ich ansprechen, versprach ich meinem Patienten.

Noch am selben Tag machte ich einen Krankenbesuch in eben jenem Hospital, und da lief mit prompt der Augenarzt über den Weg. „Auf Zeichen achten“, sagte ich mir, "gerade in der Adventszeit." Ich sprach ihn also an, er akzeptierte sofort.

Nur ein paar Tage später kam ein Anruf von meinem Patienten: Ein überschwänglicher Dank von einem überglücklichen Menschen, der sein Augenlicht wiedererhalten hatte. Der Augenarzt hatte ihm das schönste Weihnachtsgeschenk gemacht. Wie der sich gefreut hatte, das war unglaublich, herzerwärmend und ansteckend. Ein wunderschönes Weihnachtsgefühl.

Dr. Luise Hess, Darmstadt

\section{Die große oberfränkische Sprachverwirrung}

_ Als pure Mittelfränkin war ich für einige Zeit im Oberfränkischen niedergelassen. Das war nicht nur meine erste Erfahrung mit dem Hausarztwesen, sondern auch - so nah ich meiner Heimat auch war - mein erster Kontakt mit einer lebenden Fremdsprache.

Als mir in den ersten Tagen eine Mutter mit ihrem kleinen Mädchen gegenüber saß und behauptete, , es Kind göggt und kuudsd“, wartete ich, Kompetenz ausstrahlend, erst einmal längere Zeit ab, ob das Kind irgendwelche differenzialdiagnostisch verwertbaren Geräusche von sich geben würde. Am Ende musste ich aber meine eingeborene Praxispartnerin zum Übersetzen holen.

Als mir dann im nächsten Sprechzimmer ein sehr alter Bauer klagte, er sei „nobollert“, wusste ich, dass die Basis der Hausarztmedizin zuallererst eine gemeinsame Sprache ist. Alle eifrig erwor- benen Büchlein mit Tipps und Tricks für Hausärzte waren hier nutzlos.

Ach ja, Sie wollen sicher wissen, was die Patienten denn nun hatten! „Nobollert" bedeutet einfach „,heruntergefallen“. Und ein Kind, dass „göggt und kuudsd“, hustet bis zum Erbrechen. „Kutzen“" steht für „husten“, und „göggen“ bedeutet so viel wie Brechreiz haben, würgen oder sogar erbrechen.

Dr. Ingrid Hermann-Siedler, Erlangen 